\title{
Peningkatan Kompetensi Guru dalam Implementasi Pembelajaran Sains di Taman Kanak-kanak
}

\author{
Choirun Nisak Aulina ${ }^{1 *}$, Agus Salim², Fitria, Wulandari ${ }^{3}$ \\ 1,2,3 Universitas Muhammadiyah Sidoarjo \\ Email: lina@umsida.ac.id¹, agussalim@umsida.ac.id ${ }^{2}$, \\ fitriawulandari1@umsida.ac.id ${ }^{3}$ \\ *Corresponding author: lina@umsida.ac.id ${ }^{1}$
}

\begin{abstract}
ABSTRAK
Sains sangatlah dekat dengan kehidupan anak usia dini. Bagi anak-anak belajar sains adalah segala sesuatu yang menakjubkan, sesuatu yang ditemukan dan dianggap menarik serta memberi pengetahuan atau merangsangnya. Pengenalan sains untuk peserta didik TK/PAUD lebih ditekankan daripada produk (fakta,. konsep, teori, prinsip, dan hukum). Kegiatan ini dilaksanakan di TK Aisyiyah 1 Kalidawir Tanggulangin Sidoarjo. Kegiatan simulasi sains sederhana belum diterapkan di TK Aisyiyah 7 Kalidawir di minimnya kompetensi guru tentang konsep pembelajaran sains pada anak usia dini serta belum adanya buku pedoman pembelajaran sains untuk anak usia dini. Selain itu juga karena keterbatasan alat, bahan, dan media yang ada di TK Tujuan pengabdian masyarakat ini adalah untuk meningkatkan kompetensi guru tentang implementasi pembelajaran sains pada anak usia dini dengan melakukan pelatihan dan pendampingan, penyusunan buku/modul pembelajaran sains untuk anak usia dini sebagai acuan guru dalam implementasi simulasi sains pada anak usia dini serta pemenuhan media, bahan dan alat penunjang agar dapat menerapkan simulasi sains sederhana bagi anak TK. Hasil dari kegiatan pengabdian masyarakat ini 1) peningkatan kemampuan guru dari nilai rata-rata pre-test 56 meningkat pada post test menjadi 85. 2) Tersusunnya modul pembelajaran sains anak usia dini, 3) Tersedianya media, bahan dan alat penunjang iimplementasi pembelajaran.
\end{abstract}

Kosakata: Pembelajaran, Sains, Anak Usia Dini

\section{ABSTRACT}

Science is very close to the life of early childhood. For children learning science is anything that is amazing, something that is found and considered interesting and gives knowledge or stimulates it. The introduction of science to kindergarten / early childhood students is more emphasized than the product (facts, concepts, theories, principles, and laws). This activity was carried out at TK Aisyiyah 1 Kalidawir Tanggulangin Sidoarjo. Simple science simulation activities have not been implemented in Kindergarten Aisyiyah 7 Kalidawir due to the lack of teacher competence regarding the concept of science learning in early childhood and the absence of a science learning manual for early childhood. In addition, due to the limited availability of tools, materials, and media in Kindergarten, the aim of this community service is to increase teacher competence regarding the implementation of science learning in early childhood by conducting training and mentoring, compiling science learning books / modules for early childhood as a reference. teachers in the implementation of science simulations in early childhood as well as the fulfillment of media, materials and supporting tools in order to be able to apply simple science simulations for kindergarten children. The results of this community service activity 1) increase the ability of teachers from the average pre-test score of 56 to 85.2 ) The preparation of early childhood science learning modules, 3) Availability of media, materials and tools to support the implementation of learning

Keywords: Learning, Science, Early Childhood 


\section{PENDAHULUAN}

Kompetensi guru dan kesejahteraan guru adalah aspek penting untuk meningkatkan kualitas pendidikan (Susiani et al., 2017). Dalam Permendiknas No. 16 Tahun 2007 disebutkan bahwa guru harus memiliki empat standart kompetensi yakni kompetensi pedagogik, kompetensi kepribadian, kompetensi sosial dan kompetensi profesional.

Salah satu komponen dalam kompetensi pedagogi adalah kemampuan guru dalam melaksanakan pembelajaran yang properubahan meliputi aktif, kreatif, inovatif, eksperimentatif, efektif dan menyenangkan (Syaiful Sagala, 2013). Dalam melaksanakan tugas keprofesionalan guru berkewajiban merencanakan pembelajaran yang bermutu (Handayani \& Dewi, 2020). Perencanaan pembelajaran mencakup segala hal yang berkaitan dari perangkat pembelajaran, media pembelajaran serta evaluasi pembelajaran yang akan dilakukan oleh guru. Kemampuan pedagogis guru sangat berdampak terhadap keberhasilan proses pembelajaran (A. Skourdoumbis, 2014)

Program kegiatan pembelajaran di TK menurut Peraturan Menteri Pendidikan dan Kebudayaan Republik Indonesia Nomor 146 tahun 2014 adalah : (1) Nilai agama dan moral, (2) FisikMotorik, (3) Kognitif, (4) Bahasa, (5) Sosial-Emosional, dan (6) Seni ("Permendikbud RI No, 146 Tahun 2014," 2014). Kelima aspek perkembangan tersebut harus dapat terintegrasi dalam implementasi pembelajaran. Tingkat pencapaian perkembangan kognitif pada anak usia dini meliputi belajar pemecahan masalah, berfikir logis dan berfikir simbolik.

Hasil observasi pada sekolah mitra diketahui kegiatan proses belajar mengajar lebih cenderung dengan bercerita, ceramah dan mengerjakan sesuatu "paper and pencil". Kemampuan guru dalam mengembangkan kegiatan pembelajaran sains masih perlu untuk di tingkatkan (Dyah Setyaningrum Winarni, 2017)

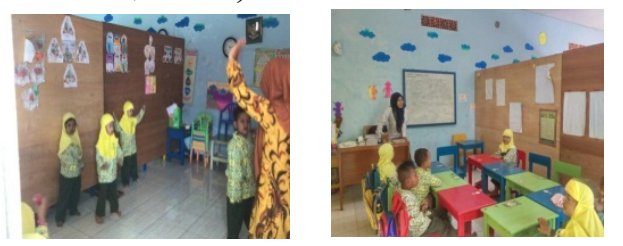

Gambar 1. Kegiatan belajar mengajar

Sains sangatlah dekat dengan kehidupan anak usia dini. Bagi anakanak belajar sains adalah segala sesuatu yang menakjubkan, sesuatu yang ditemukan dan dianggap menarik serta memberi pengetahuan atau merangsangnya. Kemampuan kognitif anak dapat ditingkatkan dengan pembelajaran sains (Fardiah et al., 2019). Hasil penelitian lain juga menunjukkan bahwa percobaan sains dapat mempengaruhi perkembangan kognitif anak (Mustika \& Nurwidaningsih, 2018).

Pengenalan sains untuk peserta didik TK/PAUD lebih ditekankan proses daripada produk (fakta,. konsep, teori, prinsip, dan hukum). 
Proses sains dikenal dengan metode ilmiah, yang secara garis besar meliputi: 1) Observasi, 2) menemukan masalah, 3) melakukan percobaan, 4) menganalisis data dan 5) mengambil kesimpulan. Menurut Montessori bahwa pembelajaran anak-anak akan efektif jika melalui pengalaman sensory/ pancaindra (Dadan Suryana, 2018). Melalui praktek langsung anakanak belajar dengan mengamati, mendengar, menyentuh bahkan juga melakukan.

Kegiatan simulasi sains sederhana sangat jarang sekali di terapkan di TK Aisyiyah 7 Kalidawir dari data Rencana Pelaksanaan Pembelajaran Harian (RPPH) diketahui dalam satu tema pembelajaran tidak lebih dari 2 kegiatan simulasi sains. Hal ini di karenakan keterbatasan kompetensi guru tentang konsep pembelajaran sains pada anak usia dini. Selain itu juga karena keterbatasan alat, bahan, dan media yang ada di TK sehingga tidak memungkinkan untuk diterapkannya program kegiatan pembelajaran Sains di TK serta belum memiliki buku/modul pembelajaran sains untuk anak usia dini sebagai acuan pembelajaran sains.

Berdasarkan permasalahan tersebut diatas, maka dilakukan upaya konkret yang dapat dilakukan yakni peningkatan kompetensi guru tentang konsep pembelajaran sains pada anak usia dini melalui pemberian pelatihan dan pendampingan pembelajaran sains, penyusunan buku/modul pembelajaran sains untuk anak usia dini bagai acuan guru dalam implementasi simulasi sains pada anak usia dini serta pemenuhan media, bahan dan alat penunjang agar dapat menerapkan simulasi sains sederhana bagi anak TK.

\section{METODE PENELITIAN}

Pelaksanaan pengabdian ini dilakukan di TK Aisyiyah 7 Kalidawir Tanggulangin selama 3 bulan. Jumlah guru di sekolah mitra ada 5 orang dengan jumlah murid 21 anak. Tahap pelaksanaan kegiatan pengabdian dilaksananakan dalam lima tahapan sebagaimana gambar 1 .

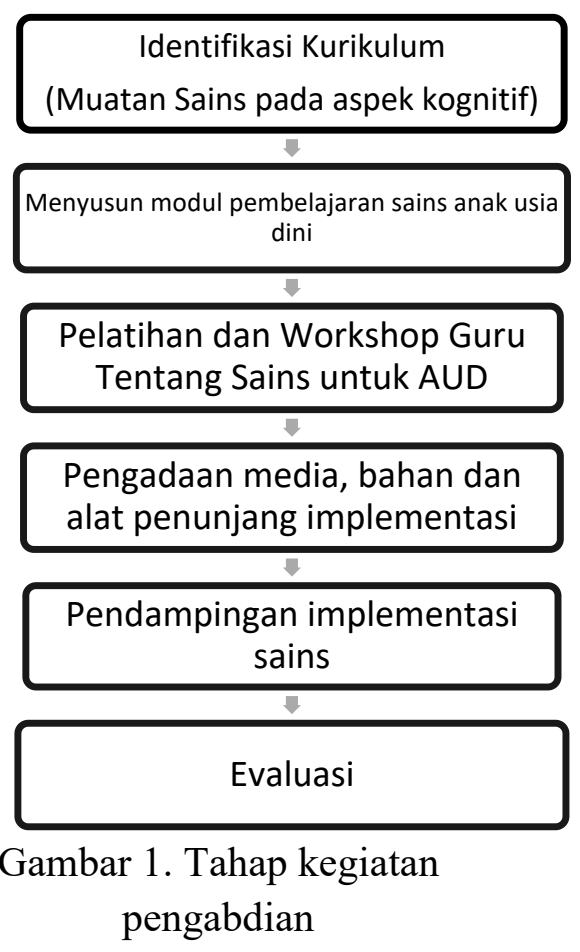

\section{HASIL DAN PEMBAHASAN}

Kegiatan pengabdian ini terdiri dari tiga bentuk kegiatan yakni :

a) Peningkatan kompetensi guru tentang konsep pembelajaran sains pada anak usia dini. 
Upaya peningkatan kompetensi guru tentang konsep pembelajaran sains sederhana pada pembelajaran di TK dilakukan dengan mengadakan pelatihan tentang pentingnya sains di ajarkan sejak dini, serta membahas permasalahan-permasalahan yang menjadi penghambat implementasi simulasi sains di pembelajaran dan hal-hal apa saja yang harus diperhatikan dalam pelaksanaan pembelajaran simulasi sains di TK. Pembelajaran literasi sains pada anak usia dini bukan hanya membuat praktek sains tanpa ada muatan, namun lebih dari itu dalam penerapan sains pada anak usia dini harus di rencanakan dengan seksama oleh guru dengan menentukan menentukan tujuan pembelajaran berbasis pada capaian perkembangan anak, dilanjutkan dengan penentuan media dan penataan lingkungan belajar (Zahro et al., 2019).

Sebelum dilakukan kegiatan pelatihan dan workshop, terlebih dahulu dilakukan pre-test dan di akhir kegiatan di lakukan post test pada guru terkait pemahaman guru tentang pembelajaran sains. Indikator kompetensi guru tentang pembelajaran sains meliputi 1) Identifikasi muatan sains pada aspek perkembangan kognitif, 2) prinsip pembelajaran sains, 3) ragam kegiatan pembelajaran sains pada AUD. Dari tiga indikator tersebut di peroleh nilai sebagaimana tabel 1 .

Tabel 1. Data pemahaman guru tentang pembelajaran sains di PAUD

\begin{tabular}{cccc}
\hline No & Guru & $\begin{array}{c}\text { Pre } \\
\text { Test }\end{array}$ & $\begin{array}{c}\text { Post } \\
\text { Tes }\end{array}$ \\
\hline 1 & Guru 1 & 40 & 80 \\
\hline 2 & Guru 2 & 65 & 85 \\
\hline 3 & Guru 3 & 60 & 90 \\
\hline 4 & Guru 4 & 50 & 85 \\
\hline 5 & Guru 5 & 65 & 85 \\
\hline \multicolumn{2}{r}{ Rata-rata } & $\mathbf{5 6}$ & $\mathbf{8 5}$ \\
\hline
\end{tabular}

Kegiatan pelatihan dan workshop ini dilaksanakan pada hari Kamis, 26 Maret 2020 dari pukul 08.00 s.d 13.00 wib. Pada kegiatan ini selain peningkatan pemahaman guru melalui penyampaian materi tentang pembelajaran sains ada anak usia dini, juga dilakukan praktek sains mengacu dari draf buku pedoman sains yang telah disusun. Beberapa kegiatan praktek sains yang dilakukukan antara lain : a. Gerhana bulan, b. Senter warna, c. Air berjalan, d. Belalai air sabun, e. Lava lamp f. Gunung meletus, dll sebagaimana gambar 2 dan 3 .
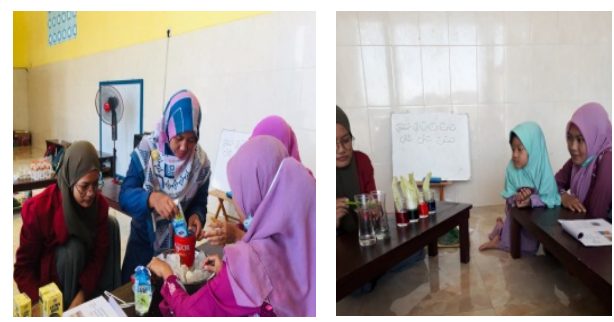

Gambar 2. Praktek sains

Pada kegiatan ini respon guru sangat baik terlihat dari ikut aktifnya semua guru dalam melakukan percobaan. Berbagai pertanyaan yang diajukan guru terkait konsep sains dari masing-masing percobaan yang dilakukan. 


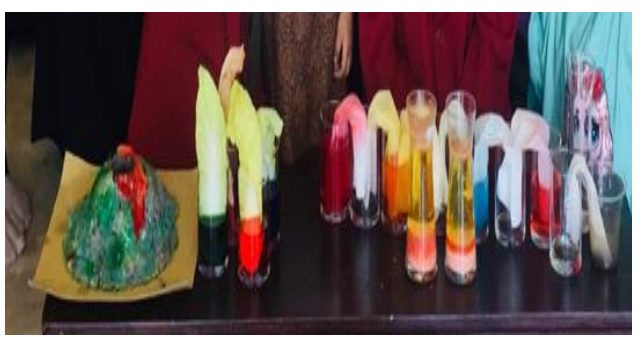

Gambar 3. Hasil praktek

b) Penyusunan

modul

pembelajaran sains untuk anak usia dini

Penyusunan

modul

pembelajaran sains dilakukan oleh tim abdimas selanjutnya dilakukan Forum Grup Discusion (FGD) dengan guru berdasar hasil pelatihan yang telah dilakukan sehingga terdapat masukan untuk pembetulan-pembetulan atau masukan guru disesuaikan dengan kondisi pada pembelajaran anak usia dini. Beberapa hal yang menjadi pertimbangan dalam praktek sains yakni keterkaitan dengan kurikulum pendidikan anak usia dini, keamanan, ketersediaan bahan.

Setelah dilakukan pengkajian kurikulum mengacu dari Permendikbud No. 137 tentang aspek perkembangan kognitif maka ditemukan tingkat pencapaian perkembangan yakni menunjukkan aktivitas yang bersifat eksploratif dan menyelidik (kog.1), mengenal sebabakibat tentang lingkungannya (kog. 8). Mengacu pada pengembangan kognitif tersebut maka tersusunlah beberapa tema simulasi sains yang ada yakni magnet, air, alam semesta, dan warna.

Dari segi keamanan juga dipertimbangkan agar tidak menggangu kesehatan, tidak mudah terbakar, tidak mengandung campuran berbahaya, warna yang digunakan juga terjamin keamanannya. Maka sangat perlu memperhatikan segala peralatan dan bahan yang digunakan.

Bahan-bahan dalam melakukan praktek sains ini juga dipilih dari yang mudah didapat disekitar atau bahkan dari yang sudah ada. Sehingga anak juga dapat praktek dirumah dengan orang tuanya setelah diajarkan oleh guru disekolah.

Modul pembelajaran sains untuk anak usia dini ini di butuhkan sebagai acuan guru agar lebih mudah dalam melakukan simulasi/praktek kegiatan pembelajaran sains sehingga kegiatan pembelajarn lebih terstruktur. Pada modul ini terdiri dari 17 panduan simulasi praktek sains antara lain : Gerhana bulan, Senter warna, Air berjalan, Belalai air sabun, Lava lamp, Gunung meletus, Merica penakut, Tisu terbang, Bola air berlari, Permen pelangi, Lemon lava, Belalai air sabun, Daun berwarna, Magic water.

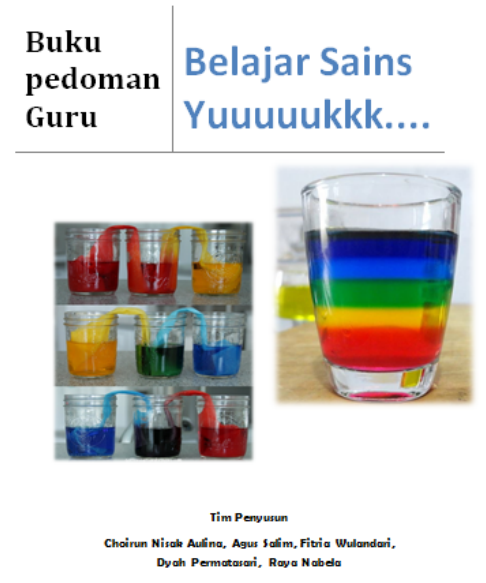

Gambar 4. Buku Modul Sains 
Modul pembelajaran sains ini dapat menjadi acuan guru dalam proses pembelajaran sains di kelas maupun di sampaikan ke orang tua sebagai kegiatan stimulasi orang tua di rumah. Pemberian stimulasi sains sesungguhnya tidak hanya tugas guru di sekolah tapi juga dapat di berikan oleh orang tua. Dengan anak terbiasa diajak untuk bermain sains maka anak terbiasa berfikir kritis (Sri Hartuti Husin, 2021).

c) Pengadaan media, bahan dan alat penunjang stimulasi sains pada anak usia dini.

Penentuan dan pengadaan media pembelajaran guna menunjang proses pembelajaran sangat penting dilakukan oleh seorang guru (Sa'ida \& Rahayu, 2018). Kegiatan penyediaan media, bahan dan alat yang belum tersedia di sekolah antara lain pengadaan gelas simulasi untuk praktek pencampuran warna, lava lamp dan beberapa praktek sains yang lain membutuhkan gelas transparan agar mudah diamati oleh siswa perubahan yang ada. Pengadaan celemek bagi siswa dan guru karena selama ini kekhawatiran yang ada ketika praktek sains adalah mengakibatkan baju anak kotor atau basah. Sehingga keberadaan celemek ini sangat bermanfaat untuk penunjang kegiatan praktek sains.

Dengan tersedianya media, bahan dan alat penunjang simulasi sains di TK maka kegiatan pembelajaran sains di TK akan lebih mudah dilaksanakan. Penyediaan peralatan dan fasilitas sangat diperlukan dalam proses pembelajaran guna menunjang terlaksananya proses belajar yang optimal (Hendarwati et al., 2017)

\section{SIMPULAN}

Pembelajaran sains sangat penting untuk diajarkan sejak dini. Dengan anak terbiasa berfikir terstruktur untuk menganalisis segala hal yang diamati, maka akan berdampak pada pola pikir anak hingga dewasa. Kegiatan pengabdian ini telah terlaksana dengan sukses dan dengan respon guru yang baik terlihat dari hasil peningkatan kompetensi guru dari nilai pre test rata 56 menjadi 85 pada post test, tersedianya modul pembelajaran sains untuk anak usia dini, serta tersedianya alat dan media penunjang praktek sains di kelas.

\section{DAFTAR PUSTAKA}

A. Skourdoumbis. (2014). Teacher effectiveness: making the difference to student achievemen? British Journal of Educational Studies, 62(2), 111126.

Dadan Suryana. (2018). Pendidikan Anak Usia Dini Stimulasi \& Aspek Perkembangan Anak (Cetakan Ke). Prenadamedia.

Dyah Setyaningrum Winarni. (2017). Analisis Kesulitan Guru Pauddalam Membelajarakan IPA pada Anak Usia Dini. EduSains: Jurnal Pendidikan Sains \& Matematika, 5(1), 12-22. http://e-journal.iainpalangkaraya.ac.id/index.php/ed usains/article/view/578

Fardiah, F., Murwani, S., \& Dhieni, N. (2019).

Meningkatkan 
Kemampuan Kognitif Anak Usia Dini melalui Pembelajaran Sains. Jurnal Obsesi: Jurnal Pendidikan Anak Usia Dini, 4(1), 133.

https://doi.org/10.31004/obsesi.v $4 \mathrm{i} 1.254$

Handayani, S. L., \& Dewi, T. U. (2020). Aksiologiya: Jurnal Pengabdian Kepada Masyarakat Pelatihan Penulisan Karya Ilmiah Bagi Guru-Guru Sekolah Dasar Untuk Meningkatkan Kompetensi Profesionalisme Guru Fungsional Guru dan Angka membuat Karya Tulis Ilmiah. 4(1).

Hendarwati, E., Setiawan, A., \& Aristiana, P. R. (2017). Aksiologiya: Jurnal Pengabdian Kepada Masyarakat Pelatihan Pembelajaran Inovatif , Penyusunan Perangkat Pembelajaran dan Pembukuan Pada Bunda PAUD kegiatan Paud Mutiara Bunda Dalam kegiatannya Paud Mutiara. 1(2), 81-91.

Mustika, Y., \& Nurwidaningsih, L. (2018). Pengaruh Percobaan Sains Anak Usia Dini terhadap Perkembangan Kognitif Anak di TK Kartika Siwi Pusdikpal Kota Cimahi. Jurnal Obsesi : Jurnal Pendidikan Anak Usia Dini, 2(1), 91.

https://doi.org/10.31004/obsesi.v $2 \mathrm{i} 1.12$

Permendikbud RI No, 146 Tahun 2014. (2014). In Kurikulum 2013 Pendidikan Anak Usia dini. Menteri Pendidikan dan Kebudayaan Republikn Indonesia.

https://doi.org/10.1017/CBO978 1107415324.004

Sa'ida, N., \& Rahayu, A. P. (2018).
Penggunaan Wabosang Sebagai Media Pendidikan Seksual Pada Anak-Anak Bantaran Sungai Jembatan Merah Surabaya. Aksiologiya: Jurnal Pengabdian Kepada Masyarakat, 2(1). https://doi.org/10.30651/aks.v2i1 .1250

Sri Hartuti Husin, Y. Y. (2021). Analisis Pembelajaran Sains Anak Usia Dini di Masa PANDEMI Covid-19. Jurnal Basicedu : Journal of Elementary Education, $5(2)$. https://doi.org/10.31004/basiced u.v5i2.780

Susiani, T. S., Salimi, M., \& Suyanto, I. (2017). Penguatan Kompetensi Guru Dalam Bidang Pendidikan Seni Melalui Lesson Study Berbasis Sekolah Di Sdit AlMadinah Kabupaten Kebumen. Jurnal Widya Laksana, 6(1), 2429.

Syaiful Sagala. (2013). Kemampuan Profesional Guru dan Tenaga Kependidikan. Alfabeta.

Zahro, I. F., Atika, A. R., \& Westhisi, S. M. (2019). Strategi Pembelajaran Literasi Sains Untuk Anak Usia Dini. Jurnal Ilmiah: POTENSIA, 4(2). https://doi.org/10.33369/jip.4.2.1 21-130 